\title{
ACOUSTICS2008/1358 \\ Acoustic measurement of bubble size and position in an ink jet printhead
}

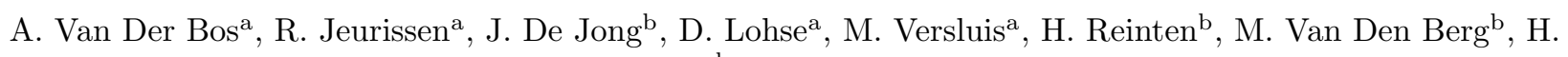 \\ Wijshoff $^{\mathrm{b}}$ and R. Stevens ${ }^{\mathrm{a}}$

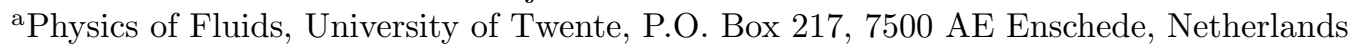 \\ ${ }^{\mathrm{b}}$ Oce Technology, P.O. Box 101, 5900 MA Venlo, Netherlands
}

An acoustic measurement method of the volume and position of a bubble in an ink jet print head, is presented. The system is driven by a piëzo actuator. The actuator is also used as a sensor by measuring the current through the piëzo. The method used to determine the volume and position of the bubble is based on a linear model of the investigated system. This model predicts the current for a given position and volume of the bubble. The inverse problem is to infer the position and volume of the bubble from the measured current through the piëzo actuator. The solution of the inverse problem is demonstrated. Thus, an acoustical measurement method of these properties is obtained. The results from the acoustical measurement method correspond closely with results from optical measurements. This indicates validity of the presented method. 